\title{
Career and Postgraduate Education Preference of Dental Students in Umm Al- Qura University, Makka City in Saudi Arabia: A Pilot Study
}

\author{
Mazen Almasri, ${ }^{1, *}$, Dalia Nourah ${ }^{2}$ \\ ${ }^{1}$ Oral Maxillofacial Surgery Department, Umm Alqura University, Makka, Saudi Arabia \\ ${ }^{2}$ Department of periodontology and basic dental science, Umm Alqura University, Makka, Saudi Arabia \\ *Corresponding author: mazen_ajm@yahoo.com
}

Received November 04, 2014; Revised December 17, 2014; Accepted January 05, 2015

\begin{abstract}
Objective: The aim of the study is to investigate the orientation and preference of dental students to postgraduate clinical and research programs. Materials and Methods: A questionnaire was distributed among male and female dental students (third, fourth, and fifth year level). The questions were directed to assess the general preference of dental students for postgraduate specialty training and education. The papers were collected and the data were extracted, tabulated, and analyzed. Results: Students diverted away from research basic science specialties that scored only $0.9 \%$, while the majority $(50.5 \%)$ indicated that they did not decide yet. According to clinical specialties Oral Maxillofacial surgery scored 25\%, orthodontics 11.6\%, and pediatrics 3.6\%. Conclusion: Most of dental students couldn't determine their preferred future graduate education. Basic science research has the least preference compared to clinical specialties, and hence, an orientation programs are needed for the dental students to guide them toward variable dental specialties.
\end{abstract}

Keywords: dental students, postgraduate, education

Cite This Article: Mazen Almasri, and Dalia Nourah, "Career and Postgraduate Education Preference of Dental Students in Umm Al- Qura University, Makka City in Saudi Arabia: A Pilot Study.” International Journal of Dental Sciences and Research, vol. 3, no. 1 (2015): 10-12. doi: 10.12691/ijdsr-3-1-3.

\section{Introduction}

Postgraduate dental education is an important pillar to improve the health care sector in Saudi Arabia. Advancing the quality of clinical skills as well as the research output will drive the medical and dental care forward by improving the service level, patient satisfaction, and reducing the complication rate [1,2]. Nowadays, the number of dental graduates in Saudi Arabia is exceeding 2500 from over 30 dental schools every year [3,4]. However, the general distribution to the different working domains has not been studied nor planned. The workforce domain in Saudi is divided into clinical service providers and basic science researchers. The clinical specialty in dental practice include Oral Maxillofacial Surgery (OMFS), orthodontics, pediatric dentistry, prosthodontics, periodontics, restorative dentistry, radiology, and endodontics, while basic science specialties include dental biomaterials, oral biology, community and pathology. Although the clinical service is provided at different heath care centers, the research aspect is considered weak.

There is no doubt that the demand for all the medical and dental specialties in Saudi Arabia is still high. However, the lack of interest to some domains cannot be neglected. This can be worse once the graduates drift way from the dental field either due to loss of interest, social reasons, or finding better paying jobs. The aim of this study is to assess if dental students are oriented toward their future after graduating from dental schools.

\section{Materials and Methods}

Prior to starting the study, a random face-to-face interview took place with random students in order to get a sense of the issue. It was found that most of the students did not have a clear idea regarding postgraduate training, and hence the research team elected to proceed with the survey in order to conduct a descriptive cross sectional study. A Questionnaire,“ tick box” sheet, was distributed among all the dental students in the faculty of dentistry at Umm Al-Qura University in Saudi Arabia. The questionnaire has close ended questions witch directed to determine students preference to ward different dental specialty. All third, forth, fifth year students were included. All data were entered into a computer and the SPSS program was used for analyzing the data.

\section{Results}

The questionnaires were circulated to the students in their classrooms, and the research team helped answering any vague points to avoid wrong feedback responses. All 
the questionnaires were collected immediately and showed a total of 115 questionnaires were collected in total. Most of the answers diverted away from the research basic science specialties that scored only $0.9 \%$, while the majority did not decide yet of future training specialty (50.5\%). Among the clinical specialties Oral maxillofacial surgery scored $25 \%$, orthodontics $11.6 \%$, and pediatric dentistry 3.6\% (Table 1) (Figure 1).

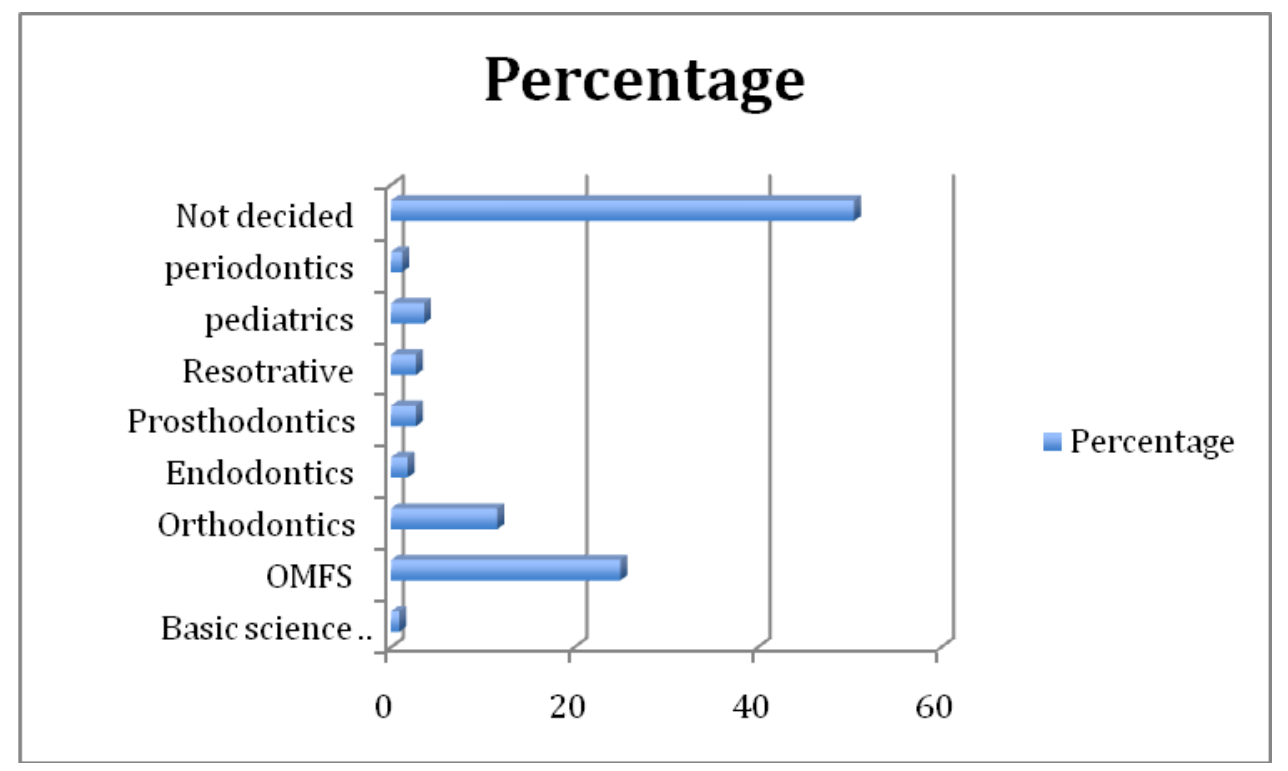

Figure 1. A graph showing the studetns preference to PGDE, where most could not decide yet, while Basic science specialties were among the least

Table 1. the preferred specialties among undergraduate dental students

\begin{tabular}{|l|c|}
\hline Specialty & Percentage \\
\hline Basic science Rsearch & 0.9 \\
\hline OMFS & 25 \\
\hline Orthodontics & 11.6 \\
\hline Endodontics & 1.8 \\
\hline Prosthodontics & 2.7 \\
\hline Resotrative & 2.7 \\
\hline pediatrics & 3.6 \\
\hline periodontics & 1.2 \\
\hline Not decided & 50.5 \\
\hline
\end{tabular}

\section{Discussion}

Distributing the health care force in the kingdom is one of the most important missions needed in the community. One of the primary steps to do so is guiding the dental students to every single dental specialty available. Dental counseling in it's current format is mainly directed toward identifying students' poor academic performance while no counseling was applied to explore students' academic talents and the potential of succeeding a specific postgraduate dental program, to our knowledge [1,5]. In addition, students are mainly driven to attend local seminars and conferences having speakers from all over the world with different topics in dentistry, but still missing a direct program mainly designed to guide undergraduate dental students to those specialties.

Now days, postgraduate dental education (PGDE) is a domain of interest to most dental graduates. The objectives of PGDE varies but it include optimizing the health care level, increase research production, distribute the service in a larger surface area in the kingdom, and increase the specialist to patient ratio around the kingdom.

Different factors contribute to the PGDE preference. Aldilighan et al suggested few of them such as gender as a major one, marrying status, and the field of interest that can fit the social needs [3]. Furthermore, the financial income, potential of growth, and the stressful working style are another factors to consider. He also found in another study that females are leaning more toward Orthodontics, Pediatrics, Endodontics, and Restorative dentistry with local PGDE to be more preferred due to the demanding social and family needs when compared to studying abroad $[3,4,6]$. On the other hand, male students preferred Orthodontics, Pediatrics, and Endodontic programs, as they might be more challenging and lucrative. [7].

The general preference of dental practitioners to basic science specialties is almost negligible, which presented only $6 \%$ in Chan et al's study sample compared to over $75 \%$ preferred clinical training [8]. Despite the fact that research based education might be an excellent career for a group of dentists seeking non-clinical, lower stressful working style, and more flexible working hours when compared to hospital on calls and emergency clinical needs [9]. Similar results were found by Sophia $\mathrm{S}$ et al, that $87.6 \%$ of the students in Harvard school of dental medicine doplan and prefer PGDE while the percentage is almost the same in a similar study performed in India as $86 \%$ of the students are planning for PGDE [10,11]. Hence, further studies are still needed along this line in order to orient the students to postgraduate dental education in general and research based studies in particular.

\section{Conclusion and Recommendations}

Basic science research is an area that does not attract students to pursue for PGDE. Factors that contribute to this finding can be the lack of knowledge toward this career path compared to clinical specialties that are more established and popular. Therefore, the establishment of a "PGDE counseling program" might be necessary. As exploring student's academic skills and their potentials during the undergraduate training can be a basic pillar 
toward the appropriate specialty. Thus, a strong research based infrastructure is necessary in every dental teaching institute [12].

\section{Acknowledgment}

The authors would like to thank our colleagues: Dr. ArwaSaggaf, DrAbrarDemyati, Dr. KhloudAlharthi and Dr. RayanYaghmour, for their regular help in research activities.

\section{References}

[1] Barnard, D., Pendlebury, M., Career Pathways. Br Dent J. 2000;10, 188(11): 583.

[2] Paquette, J.M., Sheets, C.G, The Second 'D.D.S' Degree a Formula for Practice Success. JADA. 2004; 135: 1321-1325.

[3] Aldlaighan Y., Alsadhan R., Alghamdi M., Alshahrani A., Alshahrani M., Postgraduate specialties interest, career choices and qualifications earned by male dentists graduated from King Saudi University. The Saudi Dental J, 2011; 23: 81-86.

[4] Aldlaighan Y., Albarakati S., Alhabeeb F., Alhulaily M., Career characteristic and postgraduate education of female dentist graduates of the college of dentistry at King Saud University, Saudi Arabia. The Saudi dental J, 2012; 24: 29-34.
[5] Newton, J.T., Thorogood, N., Gibbons, D.E.,. A study of the career development of male and female dental practitioners. Br. Dent. J. 2000; 188: 90-94.

[6] Ashri, N., Y., Al-Moslem, R., K., Al-Mujel, M., H.,. General Dental Practitioner's Interest In Postgraduate Dental Education, Riyadh, Saudi Arabia. JPDA 2007; 16(2): 82-98.

[7] Drugan, C.S., Chestnutt, I.G., Boyles, J.R. The current working patterns and future career aspiration of specialist trainees in dentistry. Br. Dent. J. 2004; 196: 761-765.

[8] Chan, W., C., Ng, C, H., Yiu, B. K., Liu, C. Y., Ip, C. M., Siu, H. H., Chiu, G. K., Hagg, U., Jin, L. J.,. A Survey on the Preference for Continuing Professional Dental Education amongst General Dental Practitioners who Attended the 26th Asia Pacific Dental Congress. Eur J Dent Educ 2006; 10: 210-216.

[9] Aggarwal $A^{1}$, Mehta S, Gupta D, Sheikh S, Pallagatti S, Singh R, Singla I. Dental students' motivations and perceptions of dental professional career in India. J Dent Educ. 2012 Nov; 76(11): 1532-9.

[10] Sophia Saeed, D.M.D.; Monik Jimenez, B.A., S.M.; Howard Howell, D.D.S.; NadeemKarimbux, D.M.D., M.M.Sc.; CortinoSukotjo, D.D.S., Ph.D., M.M.Sc. Which Factors Influence Students' Selection of Advanced Graduate Programs? One Institution's Experience. Journal of Dental Education June 1, 2008 vol. 72 no. 6 688-697.

[11] Shetty VB ${ }^{1}$, Shirahatti RV, Pawar P. Students' perceptions of their education on graduation from a dental school in India. J Dent Educ. 2012 Nov; 76(11):1520-6.

[12] MazenAlmasri, Sara Bukhari. Considerations to planning orthognathic surgery in different regions of Saudi and the Middle East. Am J of public Health and Res. 2014; 2: 6-9. 